\title{
Desempenho de cordeiros confinados, alimentados com dietas à base de torta de girassol
}

\author{
Deivison Novaes Rodrigues( ${ }^{(1)}$, Luciano da Silva Cabral(1), Leni Rodrigues Lima(1), \\ Joanis Tilemahos Zervoudakis ${ }^{(1)}$, Rosemary Laís Galati(1), André Soares de Oliveira ${ }^{(1)}$, \\ Dorival Pereira Borges da Costa(2) e Luiz Juliano Valério Geron ${ }^{(3)}$
}

\begin{abstract}
(1)Universidade Federal de Mato Grosso, Faculdade de Agronomia, Medicina Veterinária e Zootecnia, Avenida Fernando Corrêa da Costa, no 2.367, Boa Esperança, CEP 78060-900 Cuiabá, MT. E-mail: deivisonnr@hotmail.com, cabralls@ufmt.br, lenirodrigues_zoo@yahoo.com.br, joanisz@yahoo.com.br, laisgalati@netsite.com.br, andresoli@ufmt.br (2)Instituto Federal de Mato Grosso, Rua Tocantins, no 191 NE, Centro, CEP 78360-000 Campo Novo do Parecis, MT. E-mail: dorival.costa@cnp.ifmt.edu.br (3)Universidade do Estado de Mato Grosso, Rodovia BR 174, Km 209, Caixa Postal 181, CEP 78250-000 Pontes e Lacerda, MT. E-mail: ljgeron@yahoo.com.br
\end{abstract}

Resumo - O objetivo deste trabalho foi avaliar os efeitos da inclusão da torta de girassol na dieta de cordeiros em confinamento sobre o desempenho produtivo dos animais. Utilizaram-se 40 cordeiros sem raça definida,

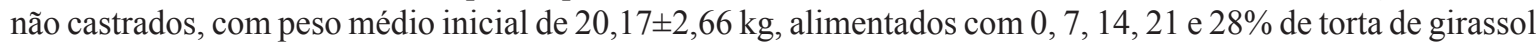
na dieta (base seca). O experimento foi conduzido em delineamento de blocos ao acaso. A inclusão de torta de girassol na dieta não alterou o consumo médio de matéria seca $(883,58 \mathrm{~g}$ por dia), a conversão alimentar $(4,40)$ e o consumo médio de água (2,59 L por dia). $\mathrm{O}$ aumento dos níveis de torta de girassol diminuiu linearmente o peso final, o ganho de peso total, o ganho de peso diário e a área de olho de lombo. O nível de inclusão de até $28 \%$ não afeta o consumo médio de matéria seca e de água, mas reduz o desempenho e a área de olho de lombo. Para obter o menor custo com a dieta, o nível de inclusão da torta de girassol pode atingir até $28 \%$ da matéria seca, quando o seu preço representar até $40 \%$ do preço da mistura entre milho e farelo de soja.

Termos para indexação: avaliação econômica, confinamento, coprodutos, custo da dieta, ovinos.

\section{Performance of feedlot lambs fed with diets based on sunflower meal}

\begin{abstract}
The objective of this work was to evaluate the effects of inclusion levels of sunflower meal in feedlot lamb diets on animal productive performance. Forty crossbreed lambs, not castrated, with average initial body weight of $20.17 \pm 2.66 \mathrm{~kg}$ were feed levels of $0,7,14,21$, and $28 \%$ of sunflower meal in the diet (dry basis). The experiment was carried out in a randomized complete block design. The inclusion of sunflower meal in the diet did not affect average dry matter intake ( $883.58 \mathrm{~g}$ per day), feed conversion (4.40), and average water intake (2.59 L per day). The increase in the levels of sunflower meal linearly reduced final weight, total weight gain, average daily gain, and loin eye area. The inclusion level of up to $28 \%$ does not affect the average intake of dry matter and water, but reduces animal performance and loin eye area. To obtain the lowest cost with the diet, the inclusion level of sunflower meal can reach up to $28 \%$ of dry matter, when its price represents up to $40 \%$ of the price of corn and soybean meal blend.
\end{abstract}

Index terms: economic evaluation, confinement, by-products, diet cost, sheep.

\section{Introdução}

A soja é a principal matéria prima utilizada para produção de biodiesel (Ferrari et al., 2005), e o método de prensagem a frio é o melhor para extração do óleo, por sua simplicidade e baixo custo. No caso do girassol, esse método extrai, em média, $57 \%$ do óleo presente na semente (Pighinelli et al., 2009). As tortas são o coproduto gerado após a extração do óleo (Goes et al., 2010).

$\mathrm{O}$ aumento no preço de alimentos tradicionais usados na dieta de ovinos confinados (Agy et al., 2012) estimulou a procura por alimentos alternativos, com valor nutritivo satisfatório e alta disponibilidade regional (Dutta et al., 2002).

A torta de girassol é uma excelente fonte de nutrientes para ovinos (Dutta et al., 2002; Oliveira et al., 2007; Goes et al., 2010; Brás, 2011; Nagalakshmi et al., 2011), por ser composta por um óleo rico em ácidos graxos poli-insaturados (65,3\%), apresenta de 22 a $33 \%$ de proteína bruta (Nagalakshmi et al., 2011; Pereira et al., 2011), além de alta digestibilidade da matéria seca $(64,56 \%)$ e da proteína bruta $(96,52 \%)$, quando se considera 5\% de taxa de passagem (Beran et al., 2007). Outro aspecto importante é a boa aceitabilidade dessa 
torta pelos animais, possivelmente por não apresentar fatores antinutricionais, o que facilita sua introdução na dieta de ovinos de forma prática e viável (Goes et al., 2010; Correia et al., 2011; Agy et al., 2012). Além disso, é interessante ressaltar que o ácido linoleico, essencial aos ruminantes (Pereira et al., 2011), representa 68\% do total de ácidos graxos presentes na torta de girassol (Brás, 2011).

Apesar de ensaios realizados para avaliar a digestibilidade da torta de girassol e o desempenho de ruminantes alimentados com esse coproduto (Dutta et al., 2002; Correia et al., 2011; Pereira et al., 2011; Agy et al., 2012), poucas informações estão disponíveis sobre seu uso na dieta de ovinos, especialmente quanto ao nível de inclusão que deve ser adotado para otimizar a produtividade de cordeiros confinados.

O objetivo deste trabalho foi avaliar os efeitos da inclusão da torta de girassol na dieta de cordeiros em confinamento sobre o desempenho produtivo dos animais.

\section{Material e Métodos}

O experimento foi conduzido no Setor de Ovinocultura da Fazenda Experimental da Universidade Federal de Mato Grosso-UFMT $\left(15^{\circ} 47^{\prime} 05^{\prime \prime} \mathrm{S} 56^{\circ} 04^{\prime} 00^{\prime \prime} \mathrm{W}\right.$, a $140 \mathrm{~m}$ de altitude), entre julho e setembro de 2011.

Foram utilizados 40 cordeiros machos não castrados, sem raça definida e deslanados, com peso corporal médio inicial de $20,17 \pm 2,66 \mathrm{~kg}$ e idade entre três e quatro meses, os quais foram distribuídos em 20 baias, com dois cordeiros em cada uma. A distribuição dos animais nas baias foi realizada em delineamento de blocos ao acaso, cujo critério de bloco foi o peso inicial dos animais. No início do experimento, os animais foram identificados, casqueados, vacinados contra clostridiose e desverminados (moxidectina a 1\%).

As dietas experimentais foram formuladas com base na matéria seca, para apresentarem $40 \%$ de volumoso e $60 \%$ de concentrado. Utilizou-se a silagem de milho como alimento volumoso, e, para compor os concentrados, foram utilizados milho moído, farelo de soja, ureia/sulfato de amônio, mistura mineral e torta de girassol. A torta foi acrescentada à dieta nos níveis de $0,7,14,21$ e $28 \%$ da matéria seca (Tabela 1). As dietas foram formuladas para apresentar 14\% de proteína bruta (Tabela 1) e proporcionar ganho médio de $200 \mathrm{~g}$ ao dia (Rocha et al., 2004; Cabral et al., 2008).

A alimentação diária foi calculada com base no peso corporal dos animais. As dietas foram fornecidas às
8 e $16 \mathrm{~h}$, na forma de mistura completa. O trato e as respectivas sobras foram monitorados diariamente, para que as sobras fossem mantidas em $10 \%$ do ofertado. A água foi fornecida ad libitum durante todo o período experimental.

As amostragens dos alimentos e das sobras ocorreram no terço inicial, médio e final do período de avaliação, durante três dias consecutivos, respectivamente aos: 17, 18 e 19 dias do início do experimento; aos 36, 37 e 38 dias; e aos 44, 45 e 46 dias. Todas as amostras obtidas foram congeladas a $-20^{\circ} \mathrm{C}$ para posteriores análises bromatológicas, no Laboratório de Nutrição Animal da UFMT.

Ao serem descongeladas, as amostras de silagem e sobras foram homogeneizadas para formar uma amostra composta para cada período, e pré-secadas em estufa de ventilação forçada de ar, a $60 \pm 5^{\circ} \mathrm{C}$, por 72 horas. Após a pré-secagem, as amostras de silagem, sobras e concentrados foram processadas a $1 \mathrm{~mm}$, em moinho tipo Willey, e submetidas às análises bromatológicas.

Tabela 1. Proporção dos ingredientes (\%) e composição centesimal das dietas experimentais, de acordo com os níveis de inclusão de torta de girassol.

\begin{tabular}{|c|c|c|c|c|c|}
\hline \multirow[t]{2}{*}{ Ingrediente } & \multicolumn{5}{|c|}{ Nível de inclusão (\%) } \\
\hline & 0 & 7 & 14 & 21 & 28 \\
\hline Silagem de milho & 40,00 & 40,00 & 40,00 & 40,00 & 40,00 \\
\hline Milho moído & 44,30 & 40,30 & 36,32 & 32,32 & 28,33 \\
\hline Farelo de soja & 13,60 & 10,60 & 7,59 & 4,58 & 1,57 \\
\hline Torta de girassol & 0,00 & 7,00 & 14,00 & 21,00 & 28,00 \\
\hline Ureia/sulfato de amônio ${ }^{(1)}$ & 0,30 & 0,30 & 0,30 & 0,30 & 0,30 \\
\hline Mistura mineral $^{(2)}$ & 1,80 & 1,80 & 1,80 & 1,80 & 1,80 \\
\hline \multicolumn{6}{|l|}{ Composição } \\
\hline Matéria seca ${ }^{(3)}$ & 65,38 & 65,66 & 65,95 & 66,23 & 66,51 \\
\hline Matéria mineral & 6,56 & 6,67 & 6,77 & 6,88 & 6,99 \\
\hline Matéria orgânica & 93,14 & 93,03 & 92,93 & 92,82 & 92,71 \\
\hline Proteína bruta & 13,77 & 13,79 & 13,81 & 13,83 & 13,85 \\
\hline Extrato etéreo & 2,20 & 2,92 & 3,64 & 4,36 & 5,08 \\
\hline Carboidratos totais & 78,01 & 77,16 & 76,32 & 75,47 & 74,62 \\
\hline Fibra em detergente neutro & 27,67 & 29,37 & 31,07 & 32,77 & 34,47 \\
\hline Fibra em detergente ácido & 16,81 & 18,20 & 19,60 & 21,00 & 22,39 \\
\hline Fibra em detergente neutro ${ }^{(4)}$ & 26,05 & 27,64 & 29,23 & 30,82 & 32,41 \\
\hline Carboidratos não fibrosos & 51,97 & 49,52 & 47,09 & 44,65 & 42,21 \\
\hline $\mathrm{N}$ insolúvel em $\mathrm{DN}^{(5)}$ & 10,23 & 10,49 & 10,76 & 11,02 & 11,28 \\
\hline $\mathrm{N}$ insolúvel em $\mathrm{DA}^{(5)}$ & 5,50 & 5,76 & 6,02 & 6,27 & 6,53 \\
\hline Nutrientes digestíveis totais $^{(6)}$ & 72,39 & 70,57 & 67,82 & 65,24 & 62,40 \\
\hline
\end{tabular}

(1)Proporção de 9:1. ${ }^{(2)}$ Mistura mineral específica para ovinos (níveis de garantia por kg: Ca, 177 g; P, 80 g; S, 20 g; Na, 108 g; Co, 40 mg; Cu, $550 \mathrm{mg}$; I, $60 \mathrm{mg}$; Se, $15 \mathrm{mg}$; Mg, $1.200 \mathrm{mg}$; Zn, $3.000 \mathrm{mg}$ ). ${ }^{(3)}$ Base na matéria natural. ${ }^{(4)}$ Corrigido para cinzas e proteína. ${ }^{(5)}$ Percentagem do $\mathrm{N}$ total; DA, detergente neutro; DA, detergente ácido ${ }^{(6)}$ Calculado segundo Cappelle et al. (2001). 
Foram determinados os teores de matéria seca (MS), matéria mineral (MM), matéria orgânica (MO), proteína bruta $(\mathrm{PB})$ (nitrogênio total x 6,25) e extrato etéreo (EE), de acordo com Silva \& Queiroz (2002). Os teores de fibra em detergente neutro (FDN) e fibra em detergente ácido (FDA) foram obtidos pelos métodos sugeridos por Van Soest et al. (1991), com uso de $\alpha$-amilase termoestável sem adição de sulfito de sódio na determinação da FDN, mas com uso de solução $8 \mathrm{~mol} \mathrm{~L}^{-1}$ de ureia. Os carboidratos totais (CT) e os carboidratos não fibrosos (CNF) dos alimentos foram calculados segundo Sniffen et al. (1992): $\mathrm{CT}=$ $100-(\% \mathrm{~PB}+\% \mathrm{EE}+\%$ Cinzas $)$ e CNF $=\mathrm{CT}-$ FDNcp, em que FDNcp representa a fibra em detergente neutro isenta de cinzas e proteína (Tabela 1). Os valores de nutrientes digestíveis totais (NDT) foram calculados de acordo com a equação proposta por Cappelle et al. (2001): NDT = 9,6134 + 0,8294DMS, em que DMS é a digestibilidade da matéria seca.

O experimento teve duração de 70 dias: 14 dias para adaptação dos animais e 56 dias para avaliação do consumo e do desempenho. O consumo de matéria seca foi obtido pela diferença entre a oferta diária de matéria seca e as respectivas sobras por baia, em que a média da baia foi dividida por dois, para se obter o consumo médio diário por animal.

Para determinar o consumo de água, utilizouse recipiente de volume previamente conhecido para abastecer os bebedouros sempre que estes apresentassem volume próximo de $10 \mathrm{~L}$; a quantidade de água fornecida era registrada para se obter o consumo diário por baia e, consequentemente, a média diária por animal. Não foi considerada a perda de água por evaporação.

No início e no final do período de avaliação, os animais foram submetidos a jejum de sólidos por 14 horas para obtenção do peso corporal inicial e do peso corporal final. Para determinar o ganho médio diário de peso, dividiu-se o ganho total pelo número de dias em confinamento. A conversão alimentar foi obtida com a divisão do consumo médio diário de matéria seca $(\mathrm{kg})$ pelo ganho médio diário de peso $(\mathrm{kg})$.

Para as variáveis de consumo e conversão alimentar, foram obtidos valores médios por baia, ou seja, cada nível de inclusão da torta de girassol foi representado por quatro baias, o que totalizou 20 parcelas para cada variável.

As medidas da área de olho de lombo foram efetuadas no longissimus dorsi entre a décima segunda e a décima terceira costela, com uso de imagens obtidas por ultrassom, no 57을 de confinamento, após o jejum. As medidas foram analisadas pelo programa Biosoft Toolbox (Biotronics Inc., Ames, IA, EUA).

$\mathrm{Na}$ análise econômica, foram considerados os custos inerentes ao quilo de matéria seca de cada alimento e sua proporção em cada dieta. Foram utilizados, como referência, os preços médios praticados no Estado de Mato Grosso em junho de 2011. O custo da tonelada de matéria seca de silagem de milho foi calculado com base no preço da produção de 100 sacas de milho por hectare, para $35 \mathrm{Mg} \mathrm{ha}^{-1}$ de matéria natural de silagem com $30 \%$ de matéria seca.

Também foram considerados o tempo (56 dias) e o ganho de peso total observados com o uso de cada dieta. Os animais foram comercializados a $\mathrm{R} \$ 3,50$ por $\mathrm{kg}$ do peso corporal vivo. Utilizou-se como indicador, na Tabela de avaliação econômica, o custo de ganho de peso, que foi equivalente ao preço mínimo de venda ( $\mathrm{R} \$$ por kg de peso corporal vivo) para equiparação do custo total de cada dieta.

Comparou-se o preço da torta de girassol ao da mistura de milho e farelo de soja, por meio de análise de sensibilidade do custo do ganho de peso corporal, conforme os níveis de inclusão da torta de girassol, para diferentes preços da torta (percentagem do preço da mistura de milho e farelo de soja).

Os dados de consumo diário de matéria seca e água, ganho de peso total e diário, conversão alimentar e área de olho de lombo foram submetidos à análise de variância e de regressão, com uso do programa estatístico Saeg (2001), em que a escolha do modelo se deu de acordo com a significância dos coeficientes da regressão a $5 \%$ de probabilidade e com o coeficiente de determinação dos modelos lineares e quadráticos.

\section{Resultados e Discussão}

Os valores de consumo de matéria seca, em valores absolutos e em percentagem do peso corporal, não foram influenciados pelos níveis de inclusão da torta de girassol (Tabela 2). Em média, o consumo diário de matéria seca foi de $883,58 \mathrm{~g}$ por animal por dia, o que representou $3,41 \%$ do peso corporal médio.

$\mathrm{O}$ consumo de matéria seca verificado foi inferior ao predito pelo National Research Council (2007), que descreve consumo de 1,0 a $1,3 \mathrm{~kg}$ de matéria seca por dia ou de 5,0 a $4,3 \%$ do peso corporal, para a categoria animal utilizada no presente trabalho. $\mathrm{O}$ fato de os 
animais avaliados não apresentarem raça definida pode ter contribuído para o baixo consumo. Segundo Cabral et al. (2008), a utilização de grupos genéticos diferentes dos utilizados na predição do consumo padrão de matéria seca - no caso, o estipulado pelo National Research Council (2007) - pode resultar na discrepância dos resultados. Ahmed \& Abdalla (2005), que avaliaram a torta de girassol como fonte proteica para cordeiros confinados, relataram consumo médio de matéria seca equivalente a $3,49 \%$ do peso corporal, próximo à média observada no presente trabalho.

A inclusão da torta de girassol não alterou o consumo diário de água e o consumo de água por $\mathrm{kg}$ de matéria seca ingerida (Tabela 2). Comumente há relação entre a ingestão de água e o consumo de matéria seca (National Research Council, 2007; Agy et al., 2012). O consumo de água para ovinos normalmente representa de duas a três vezes o valor do consumo de matéria seca (National Research Council, 2007). No presente trabalho, o consumo de água representou, em média, 2,93 vezes o consumo de matéria seca.

A inclusão da torta de girassol às dietas causou redução linear nas variáveis peso corporal final (PCF), ganho de peso total (GPT) e ganho médio diário (GMD) (Tabela 2). A cada $1 \%$ de torta de girassol adicionado, houve redução de 0,031, 0,055 e 0,980 g em PCF, GPT e GMD, respectivamente.

A diminuição no ganho de peso sem decréscimo no consumo de matéria seca, também observado por Suliman \& Babiker (2007) e Agy et al. (2012), pode ser explicada principalmente pela variação no teor de energia das dietas (Tabela 1). A adição da torta de girassol afetou os teores de NDT das dietas com reflexo direto no desempenho dos animais. A dieta sem a inclusão da torta apresentou $10 \%$ a mais de NDT que a dieta com $28 \%$ de inclusão. O consumo de NDT não atingiu as $680 \mathrm{~g}$ diárias propostas por Cabral et al. (2008), em nenhum dos tratamentos, tendo-se observado valores de $658,642,576,593$ e 530 g por dia aos níveis de $0,7,14,21$ e $28 \%$ de inclusão da torta de girassol, respectivamente.

Os CNF são a principal fonte de energia prontamente disponível no rúmen. De acordo com a disponibilidade de nitrogênio, esses carboidratos afetam o metabolismo e a multiplicação microbiana, e, consequentemente, a digestão dos alimentos, a produção de proteína microbiana e a quantidade de aminoácidos e peptídeos disponíveis para absorção no intestino delgado (Fregadolli et al., 2001). A redução na quantidade de CNF, com a inclusão da torta, foi decorrente do aumento nos teores de FDN e EE. Com 28\% de inclusão, a FDN aumentou em 19,7\% e o EE em $56,7 \%$, em comparação à dieta sem torta de girassol. A FDN é lentamente fermentada pela microbiota ruminal, se comparada aos CNF (Cabral et al., 2004), o que gera menor quantidade de ácidos graxos voláteis (AGVS) no mesmo espaço de tempo. Estes AGVS são a principal fonte de energia para o metabolismo do ruminante (Goularte et al., 2011).

$\mathrm{O}$ aumento nos teores de EE pode afetar a digestão ruminal dos alimentos, principalmente dos carboidratos fibrosos, quando comparados aos carboidratos não fibrosos (Váradyová et al., 2007). Os efeitos deletérios dos ácidos graxos, sobretudo poli-insaturados, na digestão pode ter caráter físico ou químico (Ivan et al., 2001; Váradyová et al., 2007). O efeito físico resulta da formação de uma superfície protetora nas partículas dos alimentos, que aumenta a tensão superficial e

Tabela 2. Desempenho e consumo de matéria seca (MS) e de água de cordeiros alimentados com níveis crescentes de inclusão de torta de girassol à dieta.

\begin{tabular}{|c|c|c|c|c|c|c|c|c|}
\hline \multirow[t]{2}{*}{ Variável } & \multicolumn{5}{|c|}{ Nível de inclusão (\%) } & \multirow{2}{*}{$\begin{array}{l}\text { CV } \\
(\%)\end{array}$} & \multicolumn{2}{|c|}{ Significância $^{(1)}$} \\
\hline & 0 & 7 & 14 & 21 & 28 & & Linear & Quadrática \\
\hline Consumo de matéria seca (kg por dia) & 0,91 & 0,91 & 0,85 & 0,91 & 0,85 & 10,2 & ns & ns \\
\hline Consumo de matéria seca ( $\%$ do peso corporal) & 3,50 & 3,50 & 3,28 & 3,53 & 3,27 & 9,16 & ns & ns \\
\hline Consumo de água (L) & 2,66 & 2,62 & 2,80 & 2,36 & 2,53 & 19,5 & ns & ns \\
\hline Consumo de água ( $\mathrm{L} \mathrm{kg}^{-1}$ de MS consumida) & 2,92 & 2,88 & 3,30 & 2,60 & 2,98 & 17,4 & ns & ns \\
\hline Peso corporal inicial $(\mathrm{kg})$ & 19,8 & 20,0 & 20,6 & 19,8 & 20,7 & - & - & - \\
\hline Peso corporal final (kg) & 32,3 & 31,4 & 31,1 & 31,5 & 31,2 & 11,6 & $0,05^{(2)}$ & ns \\
\hline Ganho de peso total (kg) & 12,6 & 11,4 & 10,5 & 11,7 & 10,5 & 17,4 & $0,05^{(3)}$ & ns \\
\hline Ganho médio diário (kg) & 0,22 & 0,20 & 0,19 & 0,21 & 0,19 & 17,4 & $0,05^{(4)}$ & $\mathrm{ns}$ \\
\hline Conversão alimentar ${ }^{(5)}$ & 4,10 & 4,48 & 4,51 & 4,34 & 4,53 & 9,27 & ns & ns \\
\hline
\end{tabular}

${ }^{(1)}$ Probabilidade. ${ }^{(2)} \hat{Y}=31,942-0,0318 * \mathrm{X}$ e $\mathrm{R}^{2}=0,53 .{ }^{(3)} \hat{\mathrm{Y}}=12,099-0,0551 * \mathrm{X}$ e R $\mathrm{R}^{2}=0,49 .{ }^{(4)} \hat{\mathrm{Y}}=216,04-0,9844 * \mathrm{X}$ e R ${ }^{2}=0,49 .{ }^{(5)} \mathrm{kg}$ de matéria seca

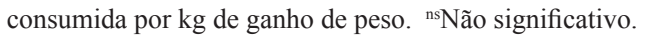


impossibilita a adesão bacteriana nessas partículas. $\mathrm{O}$ efeito químico está relacionado à toxidez dos ácidos graxos para os microrganismos. Essa toxicidade está relacionada ao aumento da fluidez da membrana celular, com consequente perda de permeabilidade seletiva e redução da viabilidade celular. A concentração máxima de EE nas dietas foi de 5,08\% da matéria seca, com a inclusão de $28 \%$ de torta de girassol. Em contraste com esses resultados, Toral et al. (2009) constataram que a digestibilidade não foi alterada pela inclusão de óleo de girassol na dieta de ovinos $(6,58 \%$ de EE).

Os valores de nitrogênio insolúvel em detergente neutro (NIDN) e de nitrogênio insolúvel em detergente ácido (NIDA) pode ter influenciado a disponibilidade de proteína para a população microbiana do rúmen. Conforme o protocolo de fracionamento utilizado pelo "Cornell net carbohydrate and protein system" (Sniffen et al., 1992; Fox et al., 2004) para determinar as frações $\mathrm{B}_{3}$ (proteína verdadeira lentamente degradada no rúmen) e $\mathrm{C}$ (proteína não degradada no rúmen e indigestível) da proteína das dietas (em que $\mathrm{B}_{3}=$ NIDN - NIDA e C = NIDA), a dieta sem a torta apresentou $4,73 \%$ de $\mathrm{B}_{3}$ e $5,50 \%$ de $\mathrm{C}$, enquanto a dieta com $28 \%$ de torta continha $4,75 \%$ de $\mathrm{B}_{3}$ e $6,53 \%$ de C. Dessa forma, a dieta com maior inclusão da torta de girassol apresentou maior quantidade de proteína não degradada no rúmen e indigestível (fração C). Suliman \& Babiker (2007) adicionaram 30\% de torta de girassol à dieta de cordeiros e não observaram diferença no ganho de peso diário e peso final dos animais; contudo, esses autores não utilizaram o farelo de soja como alimento padrão para comparação das tortas.

Embora a conversão alimentar seja uma variável dependente do ganho de peso, ela não foi afetada pelos crescentes níveis de inclusão de torta de girassol na dieta (Tabela 2). Com a diminuição da densidade energética (NDT) das dietas pela inclusão da torta, haveria tendência de aumento no consumo de matéria seca, para compensar o menor teor de energia e a menor digestibilidade das dietas com torta de girassol; no entanto, com a adição da torta, ocorreram aumentos nos teores de FDN que, aliados à menor digestibilidade da dieta, podem ter promovido repleção ruminal, o que limitou o consumo e a conversão alimentar. Rocha et al. (2004) relataram média de conversão alimentar de 4,31 kg de matéria seca consumida por $\mathrm{kg}$ de ganho, próxima da média encontrada no presente trabalho, de 4,40. Contudo, o National Research Council (2007) cita valores próximos de 4,0.
A área de olho de lombo (AOL) reduziu linearmente com a adição da torta de girassol, com decréscimo de $0,032 \mathrm{~cm}^{2}$ a cada $1 \%$ de inclusão do coproduto (Figura 1). A alta correlação entre o peso corporal vivo e a AOL, relatada por Bueno et al. (2000), é coerente com esse resultado. Por ser uma resposta direta da deposição de músculo, à medida que o peso corporal final diminuiu, com o incremento nos níveis de inclusão da torta, a AOL seguiu tendência similar e, portanto, animais com menor peso vivo tiveram menor AOL (Pereira Filho et al., 2008).

O custo da dieta com $28 \%$ de inclusão da torta de girassol e seu custo diário por animal foram respectivamente 8,92 e 15,69\% inferiores aos custos da dieta sem a inclusão da torta (Tabela 3). A dieta com $21 \%$ de inclusão proporcionou menor custo em percentagem da receita total; porém, a dieta sem a inclusão da torta proporcionou maior margem bruta (Tabela 3). A inclusão da torta de girassol diminuiu o custo por tonelada de matéria seca das dietas (R\$ por kg de matéria seca) e o custo diário por animal.

Apesar da diminuição no custo total das dietas, a receita total também diminuiu em consequência do menor ganho de peso total, o que diminuiu a margem bruta em comparação à dieta sem a inclusão da torta.

A torta de girassol representou $70 \%$ do preço da mistura milho e farelo de soja (Tabela 4), o que justifica a inclusão de $21 \%$ da torta de girassol para obter o mínimo custo de ganho de peso corporal.

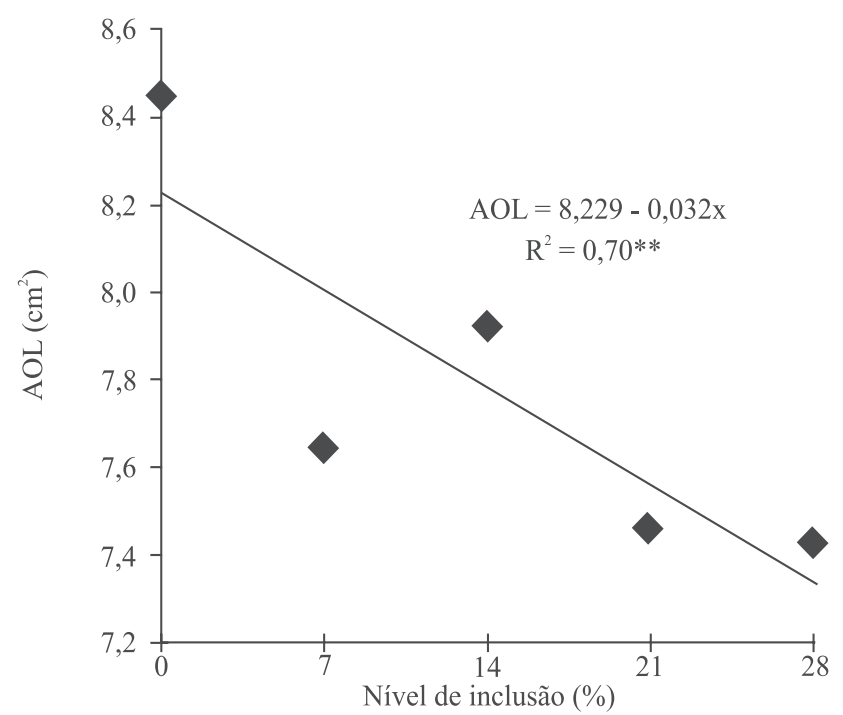

Figura 1. Área de olho de lombo (AOL) em função dos níveis de inclusão da torta de girassol à dieta de cordeiros. 
Tabela 3. Avaliação econômica das dietas de acordo com os níveis de inclusão da torta de girassol à dieta de cordeiros.

\begin{tabular}{|c|c|c|c|c|c|}
\hline \multirow[t]{2}{*}{ Indicadores } & \multicolumn{5}{|c|}{ Nível de inclusão (\%) } \\
\hline & 0 & 7 & 14 & 21 & 28 \\
\hline Custo da dieta $(\mathrm{R} \$ \text { por } \mathrm{kg})^{(1)}$ & 0,56 & 0,55 & 0,53 & 0,52 & 0,51 \\
\hline Custo diário da dieta ( $\mathrm{R} \$$ por animal) & 0,51 & 0,50 & 0,45 & 0,48 & 0,43 \\
\hline Tempo de confinamento (dias) & 56 & 56 & 56 & 56 & 56 \\
\hline Custo do ganho de peso $(\mathrm{R} \$ \text { por } \mathrm{kg})^{(2)}$ & 2,28 & 2,44 & 2,41 & 2,27 & 2,32 \\
\hline Custo total com ração $(\mathrm{R} \$)^{(3)}$ & 28,66 & 27,79 & 25,41 & 26,56 & 24,33 \\
\hline Custo total (\% da receita total) & 65,20 & 69,83 & 68,88 & 64,92 & 66,33 \\
\hline Diferença de custo total $(\%)^{(4)}$ & 0,00 & 3,03 & 11,34 & 7,33 & 15,11 \\
\hline Total da receita $(\mathrm{R} \$)^{(5)}$ & 43,96 & 39,80 & 36,89 & 40,92 & 36,68 \\
\hline Margem bruta $(\mathrm{R} \$)^{(6)}$ & 15,30 & 12,00 & 11,48 & 14,35 & 12,35 \\
\hline Margem bruta (R\$ por dia) & 0,27 & 0,21 & 0,20 & 0,26 & 0,22 \\
\hline
\end{tabular}

${ }^{(1)}$ Valores médios (R\$) por tonelada de matéria seca dos alimentos: R \$ 191,05 (silagem de milho); R \$334,33 (milho grão); R \$ 511,75 (farelo de soja); $\mathrm{R} \$ 280,00$ (torta de girassol); R $\$ 1.150,00$ (ureia) e R $\$ 1.200,00$ (sal mineral). (2) Conversão alimentar multiplicada pelo custo da dieta. ${ }^{(3)}$ Custo do ganho de peso multiplicado pelo ganho de peso total. ${ }^{(4)}$ Diferença entre o custo total da dieta com torta de girassol menos o custo total da dieta sem torta, em percentagem do custo total da dieta sem torta. ${ }^{(5)}$ Ganho de peso total multiplicado pelo preço recebido. ${ }^{\left({ }^{6}\right)}$ Receita menos o custo total com ração.

Tabela 4. Análise de sensibilidade da variação no preço da torta de girassol sobre o custo do ganho de peso corporal (R\$ por kg) de cordeiros, de acordo com os níveis de inclusão da torta de girassol.

\begin{tabular}{lccccc}
\hline $\begin{array}{l}\text { Preço } \\
(\%)^{(1)}\end{array}$ & 0 & 7 & 14 & 21 & 28 \\
\cline { 2 - 6 } Nível de inclusão (\%) \\
\hline 10 & 2,28 & 2,35 & 2,22 & 2,00 & 1,94 \\
20 & 2,28 & 2,36 & 2,25 & 2,04 & 2,00 \\
30 & 2,28 & 2,38 & 2,28 & 2,08 & 2,05 \\
40 & 2,28 & 2,39 & 2,30 & 2,12 & 2,10 \\
50 & 2,28 & 2,40 & 2,33 & 2,15 & 2,16 \\
60 & 2,28 & 2,42 & 2,36 & 2,19 & 2,21 \\
70 & 2,28 & 2,43 & 2,38 & 2,23 & 2,26 \\
72 & 2,28 & 2,44 & 2,41 & 2,27 & 2,32 \\
74 & 2,28 & 2,45 & 2,41 & 2,28 & 2,33 \\
76 & 2,28 & 2,45 & 2,42 & 2,28 & 2,34 \\
78 & 2,28 & 2,45 & 2,42 & 2,29 & 2,35 \\
80 & 2,28 & 2,45 & 2,43 & 2,30 & 2,36 \\
\hline
\end{tabular}

(1)Percentual do preço da mistura de milho e farelo de soja.

\section{Conclusões}

1. A inclusão da torta de girassol não afeta o consumo diário de matéria seca, o consumo diário de água e a conversão alimentar de cordeiros confinados, mas reduz o desempenho e a área de olho de lombo.

2. Quando o preço da torta de girassol representa até $40 \%$ do preço da mistura de milho com farelo de soja, o nível de inclusão de até $28 \%$ proporciona o menor custo de ganho de peso corporal de cordeiros; quando o preço da torta representa de 40 a $72 \%$ do preço da mistura, os menores custos são obtidos com a inclusão de até $21 \%$.

\section{Referências}

AGY,M.S.F.A.; OLIVEIRA,R.L.;RIBEIRO,C.V.DiM.; RIBEIRO, M.D.; BAGALDO, A.R.; ARAÚJO, G.G.L. de; PINTO, L.F.B.; RIBEIRO, R.D.X. Sunflower cake from biodiesel production fed to crossbred Boer kids. Revista Brasileira de Zootecnia, v.41, p.123-130, 2012. DOI: 10.1590/S1516-35982012000100019.

AHMED, M.M.M.; ABDALLA, H.A. Use of different nitrogen sources in the fattening of yearling sheep. Small Ruminant Research, v.56, p.39-45, 2005. DOI: 10.1016/j. smallrumres.2003.09.009.

BERAN, F.H.B.; SILVA, L. das D.F.; RIBEIRO, E.L. de A.; ROCHA, M.A. da; EZEQUIEL, J.M.B.; CORREA, R.A.; CASTRO, V. de S.; SILVA, K.C.F. da. Avaliação da digestibilidade de nutrientes, em bovinos, de alguns alimentos concentrados pela técnica de três estádios. Revista Brasileira de Zootecnia, v.36, p.130-137, 2007. DOI: 10.1590/S1516-35982007000100016.

BRÁS, P. Caracterização nutricional de coprodutos da extração de óleo em grãos vegetais em dietas de ovinos. 2011. 75p. Dissertação (Mestrado) - Instituto de Zootecnia, Nova Odessa.

BUENO, M.S.; CUNHA, E.A. da; SANTOS, L.E. dos; RODA, D.S.; LEINZ, F.F. Características de carcaças de cordeiros Suffolk abatidos em diferentes idades. Revista Brasileira de Zootecnia, v.29, p.1803-1810, 2000. DOI: 10.1590/ S1516-35982000000600029.

CABRAL, L. da S.; NEVES, E.M. de O.; ZERVOUDAKIS, J.T.; ABREU, J.G. de; RODRIGUES, R.C.; SOUZA, A.L.; OLIVEIRA, Í.S. de. Estimativas dos requisitos nutricionais de ovinos em condições brasileiras. Revista Brasileira de Saúde e Produção Animal, v.9, p.529-542, 2008.

CABRAL, L. da S.; VALADARES FILHO, S. de C.; DETMANN, E.; ZERVOUDAKIS, J.T.; VELOSO, R.G.; NUNES, P.M.M. Taxas de digestão das frações proteicas e de carboidratos para as silagens de milho e de capim-elefante, o feno de capim-tifton- 85 e o farelo de soja. Revista Brasileira de Zootecnia, v.33, p.1573-1580, 2004. DOI: $10.1590 / \mathrm{S} 1516-35982004000600025$. 
CAPPELLE, E.R.; VALADARES FILHO, S. de C.; SILVA, J.F.C. da; CECON, P.R. Estimativas do valor energético a partir de características químicas e bromatológicas dos alimentos. Revista Brasileira de Zootecnia, v.30, p.1837-1856, 2001. DOI: 10.1590/ S1516-35982001000700022.

CORREIA, B.R.; OLIVEIRA, R.L.; JAEGER, S.M.P.L.; BAGALDO, A.R.; CARVALHO, G.G.P.; OLIVEIRA, G.J.C.; LIMA, F.H.S.; OLIVEIRA, P.A. Consumo, digestibilidade e pH ruminal de novilhos submetidos a dietas com tortas oriundas da produção do biodiesel em substituição ao farelo de soja. Arquivo Brasileiro de Medicina Veterinária e Zootecnia, v.63, p.356-363, 2011. DOI: 10.1590/S0102-09352011000200013.

DUTTA, N.; SHARMA, K.; NAULIA, U. Use of undecorticated sunflower cake as a critical protein supplement in sheep and goats fed wheat straw. Asian-Australasian Journal of Animal Sciences, v.15, p.834-837, 2002.

FERRARI, R.A.; OLIVEIRA, V. da S.; SCABIO, A. Biodiesel de soja - taxa de conversão em ésteres etílicos, caracterização físico-química e consumo em gerador de energia. Química Nova, v.28, p.19-23, 2005. DOI: 10.1590/S0100-40422005000100004.

FOX, D.G.; TEDESCHI, L.O.; TYLUTKI, T.P.; RUSSEL, J.B.; VAN AMBURGH, M.E.; CHASE, L.E.; PELL, A.N.; OVERTON, T.R. The Cornell net carbohydrate and protein system model for evaluating herd nutrition and nutrient excretion. Animal Feed Science and Technology, v.112, p.29-78, 2004. DOI: 10.1016/j. anifeedsci.2003.10.006

FREGADOLLI, F.L.; ZEOULA, L.M.; PRADO, I.N. do; BRANCO, A.F.; CALDAS NETO, S.F.; KASSIES, M.P.; DALPONTE, A.O. Efeito das fontes de amido e nitrogênio de diferentes degradabilidades ruminais. 1. Digestibilidades parcial e total. Revista Brasileira de Zootecnia, v.30, p.858-869, 2001. DOI: $10.1590 / \mathrm{S} 1516-35982001000300035$.

GOES, R.H. de T. e B.; SOUZA, K.A. de; PATUSSI, R.A.; CORNELIO, T. da C.; OLIVEIRA, E.R. de; BRABES, K.C. da S. Degradabilidade in situ dos grãos de cambre, girassol e soja, e de seus coprodutos em ovinos. Acta Scientiarum. Animal Sciences, v.32, p.271-277, 2010. DOI: 10.4025/actascianimsci.v32i3.7913.

GOULARTE, S.R.; ÍTAVO, L.C.V.; SANTOS, G.T.; ÍTAVO, C.C.B.F.; OLIVEIRA, L.C.S.; FAVARO, S.P.; DIAS, A.M.; TORRES JUNIOR, R.A.A.; BITTAR, C.M.M. Ácidos graxos voláteis no rúmen de vacas alimentadas com diferentes teores de concentrado na dieta. Arquivo Brasileiro de Medicina Veterinária e Zootecnia, v.63, p.1479-1486, 2011. DOI: 10.1590/ S0102-09352011000600027.

IVAN, M.; MIR, P.S.; KOENIG, K.M.; RODE, L.M.; NEILL, L.; ENTZ, T.; MIR, Z. Effects of dietary sunflower seed oil on rumen protozoa population and tissue concentration of conjugated linoleic acid in sheep. Small Ruminant Research, v.41, p.215-227, 2001. DOI: 10.1016/S0921-4488(01)00220-6.

NAGALAKSHMI, D.; DHANALAKSHMI, K.; HIMABINDU, D. Replacement of groundnut cake with sunflower and karanj seed cakes on performance, nutrient utilisation, immune response and carcass characteristics in Nellore lambs. Small
Ruminant Research, v.97, p.12-20, 2011. DOI: 10.1016/j. smallrumres.2011.02.003.

NATIONAL RESEARCH COUNCIL. Nutrient requirements of small ruminants: sheep, goats, cervids, and new world camelids. Washington: National Academy Press, 2007. 362p.

OLIVEIRA, M. Dal S. de; MOTA, D.A.; BARBOSA, J.C.; STEIN, M.; BORGONOVI, F. Composição bromatológica e digestibilidade ruminal in vitro de concentrados contendo diferentes níveis de torta de girassol. Ciência Animal Brasileira, v.8, p.629-638, 2007.

PEREIRA FILHO, J.M.; RESENDE, K.T. de; TEIXEIRA, I.A.M. de A.; SILVA SOBRINHO, A.G. da; YAÑEZ, E.A.; FERREIRA, A.C.D. Características da carcaça e alometria dos tecidos de cabritos F1 Boer x Saanen. Revista Brasileira de Zootecnia, v.37, p.905-912, 2008. DOI: 10.1590/S1516-35982008000500019.

PEREIRA, E.S.; PIMENTEL, P.G.; BOMFIM, M.A.D.; CARNEIRO, M.S. de S.; CÂNDIDO, M.J.D. Torta de girassol em rações de vacas em lactação: produção microbiana, produção, composição e perfil de ácidos graxos do leite. Acta Scientiarum. Animal Sciences, v.33, p.387-394, 2011. DOI: 10.4025/ actascianimsci.v33i4.113.

PIGHINELLI, A.L.M.T.; PARK, K.J.; RAUEN, A.M.; OLIVEIRA, R.A. de. Otimização da prensagem de grãos de girassol e sua caracterização. Revista Brasileira de Engenharia Agrícola e Ambiental, v.13, p.63-67, 2009. DOI: 10.1590/ S1415-43662009000100009.

ROCHA, M.H.M. da; SUSIN, I.; VAZ PIRES, A.; FERNANDES JUNIOR, J. de S.; MENDES, C.Q. Performance of Santa Ines lambs fed diets of variable crude protein levels. Scientia Agricola, v.61, p.141-145, 2004. DOI: 10.1590/S0103-90162004000200003.

SAEG: sistema de análises estatísticas e genéticas. Viçosa: UFV, 2001.

SILVA, D.J.; QUEIROZ, A.C. Análise de alimentos: métodos químicos e biológicos. 3.ed. Viçosa: UFV, 2002. 235p.

SNIFFEN, C.J.; O'CONNOR, J.D.; VAN SOEST, P.J.; FOX, D.G.; RUSSEL, J.B. A net carbohydrate and protein system for evaluating cattle diets. II. Carbohydrate and protein availability. Journal of Animal Science, v.70, p.3562-3577, 1992.

SULIMAN, G.M.; BABIKER, S.A. Effect of diet-protein source on lamb fattening. Research Journal of Agriculture and Biological Sciences, v.3, p.403-408, 2007.

TORAL, P.G.; BELENGUER, A.; FRUTOS, P.; HERVÁS, G. Effect of the supplementation of a high-concentrate diet with sunflower and fish oils on ruminal fermentation in sheep. Small Ruminant Research, v.81, p.119-125, 2009. DOI: 10.1016/j. smallrumres.2008.12.009

VAN SOEST, P.J.; ROBERTSON, J.B.; LEWIS, B.A. Methods for dietary fiber, neutral detergent fiber, and nonstarch polysaccharides in relation to animal nutrition. Journal of Dairy Science, v.74, p.3583-3597, 1991. DOI: 10.3168/jds.S0022-0302(91)78551-2.

VÁRADYOVÁ, Z.; KIŠIDAYOVÁ, S.; SIROKA, P.; JALČ, D. Fatty acid profiles of rumen fluid from sheep fed diets supplemented with various oils and effect on the rumen ciliate population. Czech Journal of Animal Science, v.52, p.399-406, 2007.

Recebido em 13 de setembro de 2012 e aprovado em 25 de março de 2013

Pesq. agropec. bras., Brasília, v.48, n.4, p.426-432, abr. 2013

DOI: $10.1590 / \mathrm{S} 0100-204 X 2013000400011$ 